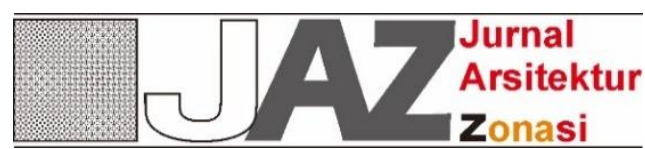

http://ejournal.upi.edu/index.php/jaz - e-mail: jurnal_zonasi@upi.edu doi.org/10.17509/jaz.v4i1.31733

\title{
GALERI SEBAGAI WADAH POTENSI PENGEMBANGAN HOME INDUSTRI DI KAWASAN KELURAHAN KOPO KOTA BANDUNG
}

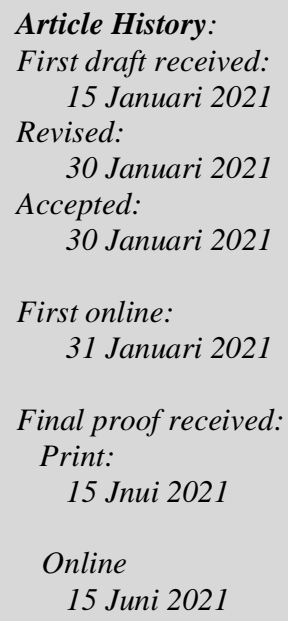

Jurnal Arsitektur ZONASI is indexed and listed in several databases:

SINTA 4 (Arjuna)

GARUDA (Garda Rujukan Digital)

Google Scholar

Dimensions

oneSearch

BASE

Member:
Crossref
RJI
APTARI
FJA (Forum Jurna Arsitektur)
IAI
AJPKM

Member:

Crossref

APTARI

IAI

\section{Elgri Yugawati Wisesa ${ }^{1}$}

${ }^{1}$ Arsitektur S-2, Program Studi Arsitektur S-2 FPTK Universitas Pendidikan Indonesia, Bandung, Indonesia

Jl. Dr. Setiabudhi No. 207-229 Bandung, Indonesia, 40154

Email: elgri.wisesa@upi.edu

Abstract: This gallery design aims to accommodate 206 Small and Medium Enterprises, 5 food stalls, 32 street vendors, 3 food industries, 8 handicraft industries and 3 clothing industries. This is because there is no place for the potential of Home Industry to become a means of developing new business actors, both micro and macro. This gallery design is located in Kopo Village with an area of 28 hectares consisting of $12 \mathrm{RW}$ and $86 \mathrm{RT}$ which are spatially located in slum areas scattered in Kopo Village according to the Bandung Mayor's Decree regarding Housing and slum settlements in Bandung City.

The method used in planning and designing this gallery is a participatory approach. A participatory approach is used as an approach that is closer to the community in order to create a sense of belonging in the Kopo District community. Data collection techniques used were interviews and field observations. As well as data collection from the RPJMD and BPS Kota Bandung. The purpose of planning and designing the Gallery building is to realize its potential container by mobilizing the creative economy community (Ekraf) and jointly building facilities and infrastructure to support the creative economy (Ekraf) in Kopo Village.

Keywords: Gallery design, street vendors, handicraft, slum settlement

Abstrak: Perancangan Galeri ini bertujuan untuk mewadahi 206 UKM, 5 Warung makan, 32 Pedagang kaki lima (PKL), 3 Industri Makanan, 8 Industri Kerajinan dan 3 Industri Pakaian. Karena belum ada wadah potensi Home industry yang menjadi sarana berkembangnya pelaku usaha baru baik itu mikro ataupun makro. Perancangan Galeri ini bertempat di kelurahan Kopo dengan luas wilayah mencapai 28 Ha yang terdiri dari 12 RW dan 86 RT yang secara spasial berada di kawasan permukiman kumuh yang tersebar di Kelurahan Kopo sesuai dengan Kepwal Walikota Bandung tentang perumahan dan permukiman kumuh di Kota Bandung.

Metode yang digunakan pada perencanaan dan perancangan galeri ini adalah pendekatan partisipatif. Pendekatan partisipatif di gunakan sebagai pendekatan yang lebih dekat dengan masyarakat agar memunculkan sense of belonging dari masyarakat kawasan kelurahan Kopo. Teknik pengambilan data yang dilakukan adalah melakukan wawancara dan observasi lapangan. Serta mengumpulkan data dari RPJMD dan BPS Kota Bandung. Tujuan perencanaan dan perancangan gedung Galeri yaitu mewujudkan wadah potensi dengan menggerakan komunitas ekonomi kreatif (ekraf) dan bersama-sama untuk membangun sarana dan pra-sarana sebagai penunjang ekonomi kreatif (ekraf) di Kelurahan Kopo

Kata Kunci: maksimal; empat; kata; kunci. (10pt Times New Roman) 


\section{Pendahuluan (12pt Times New Roman)}

Perancangan Galeri ini bertujuan untuk mewadahi 206 UKM, 5 Warung makan, 32 Pedagang kaki lima (PKL), 3 Industri Makanan, 8 Industri Kerajinan dan 3 Industri Pakaian. Karena belum ada wadah potensi Home industry yang menjadi sarana berkembangnya pelaku usaha baru baik itu mikro ataupun makro. Perancangan Galeri ini bertempat di kelurahan Kopo dengan luas wilayah mencapai 28 Ha yang terdiri dari 12 RW dan 86 RT yang secara spasial berada di kawasan permukiman kumuh yang tersebar di Kelurahan Kopo sesuai dengan Kepwal Walikota Bandung No.648/kep.286.Distarcip/2015 tentang perumahan dan permukiman kumuh di Kota Bandung.

Perancangan Galeri kedepannya mewadahi potensi sosial dan ekonomi dari pelaku usaha agar bisa berkolaborasi mengembangkan usahanya, mengangkat produk kearifan lokal, meningkatkan produktivitas dan daya saing usaha ekonomi, mengadakan perencanaan bisnis dan pengembangannya dengan diadakannya ruang pusat bisnis yang berkolaborasi dengan bank, memperlihatkan proses pembuatan karya untuk di pasarkan dengan disediakannya ruang workshop, pameran dan area komersial. Selain itu disediakan diorama sebagai rekam jejak citra kampung kota di kawasan kelurahan Kopo agar menjadi kenangan dan pembelajaran kepada generasi selanjutnya. Metode yang di gunakan pada perencanaan dan perancangan galeri ini adalah pendekatan partisipatif. Pendekatan partisipatif di gunakan sebagai pendekatan yang lebih dekat dengan masyarakat agar memunculkan sense of belonging dari masyarakat kawasan kelurahan Kopo. Teknik pengambilan data yang dilakukan adalah melakukan wawancara dan observasi lapangan. Serta mengumpulkan data dari RPJMD dan BPS Kota Bandung. Tujuan perencanaan dan perancangan gedung Galeri yaitu mewujudkan wadah potensi dengan menggerakan komunitas ekonomi kreatif (ekraf) dan bersama-sama untuk membangun sarana dan prasarana sebagai penunjang ekonomi kreatif (ekraf) di Kelurahan Kopo.

\section{Tinjauan Pustaka}

\subsection{Urbanisasi pada permukiman kumuh}

Kata "kumuh" sering digunakan untuk mendeskripsikan permukiman informal di dalam kota yang perumahannya tidak layak huni dengan kondisi yang memprihatinkan(Permana dkk., 2017)

. Hunian yang sesak, dengan banyak orang berdesakan di ruang keluarga yang sangat kecil. Permukiman kumuh bukanlah fenomena baru. Mereka telah menjadi bagian dari sejarah hampir semua kota, terutama selama fase urbanisasi dan industrialisasi. Umumnya permukiman kumuh merupakan satu-satunya jenis permukiman yang terjangkau dan dapat diakses oleh masyarakat yang tdak mampu di kota, apalagi persaingan untuk mendapatkan tanah dan keuntungan sangat ketat. Alasan utama pemekaran daerah kumuh adalah pola urbanisasi yang cepat dan tidak inklusif yang dipicu oleh peningkatan migrasi pedesaan ke daerah perkotaan(UN-Habitat, 2003).

Pertumbuhan penduduk perkotaan yang berkelanjutan mengakibatkan berlanjutnya urbanisasi, yaitu meningkatnya proporsi penduduk yang tinggal di daerah perkotaan. Selama dekade terakhir, tingkat urbanisasi telah meningkat di semua wilayah geografis utama dunia, dengan proporsi populasi yang tinggal di daerah perkotaan meningkat dari 46,6 persen pada tahun 2000 menjadi 50,6 persen pada tahun 2010. Selama periode yang sama populasi perkotaan di negara-negara berkembang meningkat dari 40,1 persen menjadi 45,3 persen. Populasi perkotaan negara berkembang diharapkan mencapai 50,5 persen pada tahun 2020 (UN-Habitat, 2003).

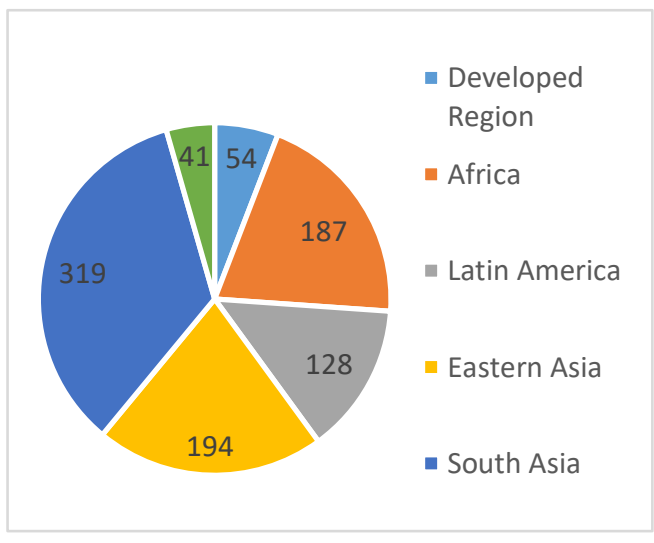

Gambar 1 Distribusi penghuni permukiman kumuh (juta) menurut wilayah, 2000 - 2010 Sumber; UN-Habitat 
Dari segi jumlah, Asia mendominasi dengan penghuni daerah kumuh terbanyak berada di Asia. Namun, perkiraan saat ini menegaskan bahwa kemajuan yang dibuat untuk mencapai target permukiman kumuh belum cukup untuk mengatasi pertumbuhan permukiman informal di daerah berkembang. Upaya untuk mengurangi jumlah penghuni permukiman kumuh tidak memuaskan dan juga tidak memadai. Kesenjangan perkotaan yang cukup besar masih terlihat, karena jumlah penghuni permukiman kumuh terus meningkat. Hampir sepertiga penduduk perkotaan di kawasan berkembang masih tinggal di permukiman kumuh.

\subsubsection{Kriteria pemukiman kumuh}

Tingkat permukiman kumuh kota dapat diukur dengan variabel - variabel yang menyebabkan kekumuhan. Kriteria permukiman kumuh merupakan kriteria yang digunakan untuk menentukan kondisi kekumuhan pada perumahan kumuh dan permukiman kumuh yang dibagi menjadi 3 klasifkasi yaitu; ringan, sedang, dan berat (Menteri Pekerjaan Umum dan Perumahan Rakyat Republik Indonesia, 2016), (Fitria \& Setiawan, 2014), (Febrion et al., 2020) .

Kriteria perumahan kumuh dan permukiman kumuh ditinjau dari aspek - aspek meliputi :

1. Aspek fisik (Bangunan Gedung, Jalan Lingkungan, Penyediaan Air Minum, Drainase Lingkungan, Pengelolaan Air Limbah, Pengelolaan Persampahan, dan Proteksi Kebakaran).

2. Aspek Tipologi (di atas air, di tepi air, di dataran rendah, di perbukitan, dan di daerah rawan bencana).

3. Aspek Lokasi (Kondisi kekumuhan dan Legalitas tanah).

4. Aspek Non Fisik (Nilai strategis lokasi, Kependudukan, dan Kondisi sosial, ekonomi, dan budaya).

\subsection{Ekonomi Kreatif Berbasis Komunitas}

Ekonomi kreatif adalah sebuah konsep dalam merealisasikan pembangunan ekonomi berkelanjutan yang berbasis kreativitas(Christiyani, 2019; Purnomo et al., n.d.). Pemanfaatan sumber daya yang tidak hanya terbarukan, melainkan tidak terbatas, yaitu ide, gagasan, bakat atau talenta dan kreativitas(Ekosistem et al., 2014). Nilai ekonomi dari suatu produk atau jasa di era kreatif tidak ditentukan oleh bahan baku dan sistem produksi seperti pada era industri, tetapi lebih kepada pemanfaatan kreativitas dan penciptaan inovasi melalui pengembangan ilmu teknologi yang semakin maju(Hutomo et al., 2000; Usaha et al., 2019).

Usaha mikro kecil dan menengah (UMKM) dewasa ini menjadi target untuk peningkatan ekonomi di semua kalangan masyarakat. Tidak memerlukan tempat yang luas, UMKM di memberikan ruang bagi ibu rumah tangga dan calon pengusaha muda untuk menyalurkan hobi dan menghasilkan uang. Industri tidak dapat lagi bersaing di pasar global dengan mengandalkan harga dan atau kualitas produk industri, tetapi bersaing dengan berbasiskan inovasi, kreativitas dan imajinasi manusia(Aset et al., 2017) (Wijaya dkk., 2017)

\subsubsection{Kegiatan Karang Taruna sebagai Motor Ekonomi Kreatif}

Pengangguran merupakan permasalahan yang masih harus diatasi oleh Pemerintah Pusat dan jajaran pemerintah daerah. Berbagai cara dalam mengatasi permasalahan ini sudah ditempuh oleh pemerintah namun belum mampu untuk diselesaikan(Permana, 2012a)(E et al., 2007) . Pengangguran ini muncul karena adanya fenomena ketidaksesuaian antara permintaan tenaga kerja dan penawaran tenaga kerja(Niken Fitria \& Setiawan, 2014)(Permana, 2012b). Permasalahan pengangguran sangat penting untuk diperhatikan karena pengangguran berpontensi menimbulkan kerawanan berbagai kriminal dan gejolak sosial, politik dan kemiskinan(E et al., 2007; Ekosistem et al., 2014). Pada saat setiap orang harus mengkonsumsi bahan pokok seperti beras, gula dan lain-lain, bahan sandang seperti pakaian, sepatu, juga energi listrik, jasa dan sebagainya setiap hari, tetapi hal tersebut tidak mampu terpenuhi karena permasalahan tidak mempunyai penghasilan.

Program yang menarik perhatian masyarakat terkait peningkatan ekonomi bisa berawal dari keinginan masyarakat untuk mengadakan perubahan hingga pengusulan gerakan ekonomi kreatif berbasis komunitas. Hal tersebut perlu pendampingan yang terarah dari awal sampai pemeliharaan produktivitas penggiat usaha. Apalagi disetiap Kelurahan memiliki organisasi pemuda yaitu karang taruna.

Karang taruna bisa membuat program untuk bekerja sama dengan Program Pemerintah setempat dan masyarakat untuk upaya pengurangan pengangguran(Ekosistem et al., 2014). Efektivitas program pengurangan pengangguran dapat dilihat dengan 4 variabel-variabel yaitu sebagai berikut(Christiyani, 2019) (Permana dkk., 2019);(E et al., 2007; Karir, 2013).
a. Ketepatan Sasaran Program
b. Sosialisasi Program
c. Tujuan Program
d. Pemantauan 
Sedangkan untuk mengetahui perubahan kondisi ekonomi masyarakat yang mengikuti program pengurangan pengangguran digunakan sebuah konsep sebelum dan sesudah mengikuti program yaitu menggunakan alat analisis statistik beda dua rata-rata (Christiyani, 2019) (Wijaya dan Permana, 2018)

\section{Metode Penelitian}

\subsection{Metode analisis}

Metode yang digunakan dalam penelitian ini adalah metode deskriptif kualitatif, yaitu penggambaran atau menjelaskan fakta - fakta yang ada di lapangan dengan cara menganalisis serta membahasnya secara luas sehingga dapat menemukan hasil dan kesimpulan. Penelitian ini akan menganalisis klasifikasi pemukiman kumuh berdasarkan literatur yang nantinya akan membahas mengenai kriteria hunian kumuh dan pemukiman dengan kejadian penyakit TB.

\subsection{Metode pengumpulan data}

Untuk metode pengambilan data, penelitian menggunakan data primer dan sekunder. Data primer adalah kegiatan untuk mengamati objek keadaan sekitar, dengan maksud merasakan serta melihat langsung sehingga bisa memahami apa yang terjadi. Observasi juga dilakukan untuk mengamati keadaan fisik, tipologi, lokasi, dan non fisik, seperti bentuk dan letak bangunannya, keadaan sekitar bangunan, iklim nya, dan sosial, ekonomi, dan budaya yang mempengarui kejadian penyakit TB. Observasi bisa dimanfaatkan dengan cara menulis disebuah catatan, atau bisa juga dengan dokumentasi yang berupa digital seperti foto, video, atau rekaman sehingga hal ini bertujuan untuk menguatkan penelitian ketika mengambil data. Sedangkan untuk data sekunder adalah dengan diperbanyaknya mencari literatur dari jurnal, website, serta buku yang membahas tentang kondisi kesehatan pada bangunan di pemukiman kumuh.

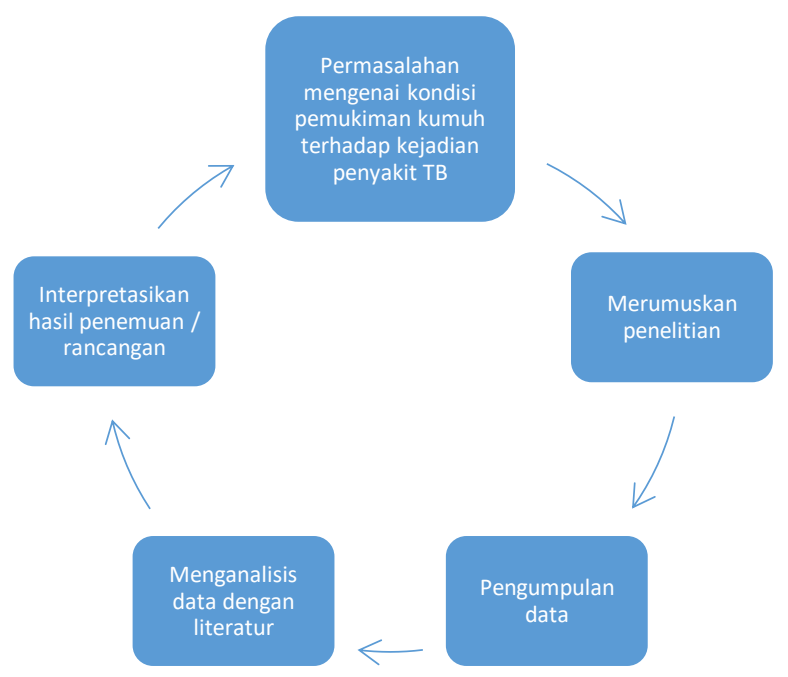

Gambar 2 Diagram metode pengumpulan data

\section{Hasil dan Pembahasan}

Kondisi percampuran tata guna lahan untuk kegiatan komersil adalah bagian dari survival kampung kota untuk menciptakan kota yang mengarah ke liveable (Foran, 2009; Health \& Quality, 2003; Purwanto \& Sukawi (Universitas Diponegoro), 2009). Permukiman kumuh adalah perumahan tidak layak huni karena tidak memenuhi syarat dan mengalami penurunan fungsi (INDONESIA), 2011). Penyebab Kumuh sebuah kawasan adalah faktor tingkat penghasilan status kepemilikan dan tempat tinggal(Rofiana, 2015; Surtiani, 2006). Oleh karena itu perancang harus memperhatikan aspek yang akan dijadikan acuan dalam merancang dengan prinsip perancangan yang dapat mewadahi potensi dari kelurahan kopo sebagai berikut (profil kelurahan Kopo).

\subsection{Data dan Analisis Tapak}

Tapak Perancangan terletak di Jalan Madesa yang merupkan jalan lingkungan RT 08/RW 12 Kelurahan Kopo yang terhubung dengan Jalan Nasional. Kawasan ini merupakan Kawasan yang masuk kedalam SK Kumuh Perwal Wali Kota Bandung. 


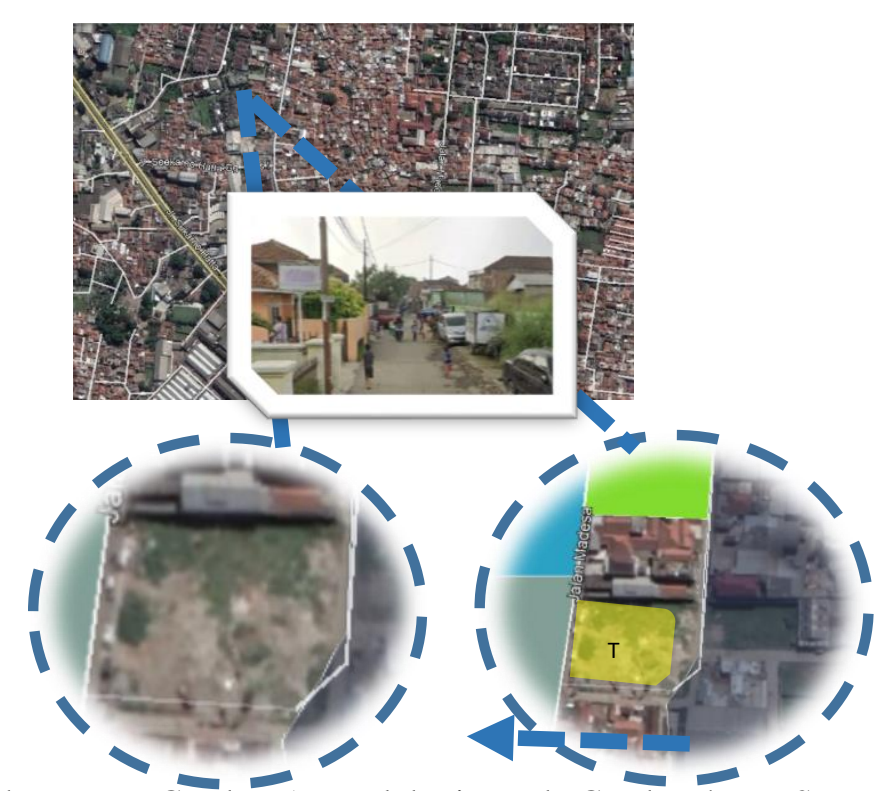

Gambar 3 Peta Lokasi Kelurahan Kopo Gambar 5 Peta lokasi Tapak Gambar 4 Peta Suasana Lokasi Tapak

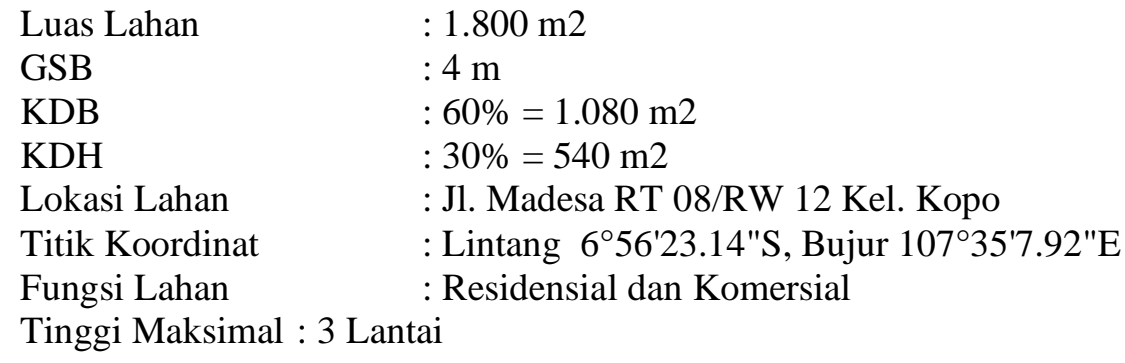

\subsubsection{Kelurahan Kopo}

a. Kondisi kependudukan menurut sosial dan budaya berdasarkan mata pencaharian

Jumlah penduduk berdasarkan struktur mata pencaharian di Kelurahan Kopo didominasi dengan mata pencaharian sebagai pelajar dengan jumlah 8.125 jiwa. Untuk lebih lengkap nya dapat dilihat melalui tabel dibawah ini:

Tabel 1 Jumlah penduduk berdasarkan mata pencaharian

\begin{tabular}{|c|l|c|c|c|}
\hline No & Mata Pencaharian & L & P & Jumlah \\
\hline $\mathbf{1}$ & Pegawai Negeri & 725 & 814 & 1.539 \\
\hline $\mathbf{2}$ & ABRI, POLRI & 418 & 550 & 968 \\
\hline $\mathbf{3}$ & Pegawai Swasta & 1.215 & 1.680 & 2.895 \\
\hline $\mathbf{4}$ & Tani & 328 & 258 & 586 \\
\hline $\mathbf{5}$ & Dagang & 1.959 & 1.582 & 3.541 \\
\hline $\mathbf{6}$ & Pelajar & 3.212 & 4.913 & 8.125 \\
\hline $\mathbf{7}$ & Mahasiswa & 1.193 & 1.082 & 2.275 \\
\hline $\mathbf{8}$ & Pensiunan & 1.047 & 630 & 1.677 \\
\hline $\mathbf{9}$ & Lain-lain & 5.654 & 3.942 & 9.596 \\
\hline & Jumlah & $\mathbf{1 5 . 7 5 1}$ & $\mathbf{1 5 . 4 5 1}$ & $\mathbf{3 1 . 2 0 2}$ \\
\hline
\end{tabular}


b. Kondisi kependudukan menurut sosial dan budaya berdasarkan masyarakat berpenghasilan rendah (MBR)

Kondisi sosial keluarga MBR di Kelurahan Kopo mencapai 29046 jiwa, dimana jumlah MBR terbesar berada di kawasan kumuh kelurahan Kopo yaitu RW 07 mencapai hingga 1105 jiwa dan yang paling rendah berada di RW 05 yaitu 119 jiwa. Untuk lebih lengkapnya dapat dilihat melalui table di bawah ini:

Tabel 2 Jumlah penduduk berdasarkan MBR

\begin{tabular}{|c|c|c|c|c|c|}
\hline \multirow{2}{*}{ No } & \multirow{2}{*}{ Kelurahan } & \multicolumn{2}{|c|}{ Jumlah } & \multirow{2}{*}{$\begin{array}{c}\text { Jumlah } \\
\text { Penduduk }\end{array}$} & \multirow{2}{*}{ Jumlah MBR } \\
\hline & & RT & RW & & \\
\hline 1 & \multirow{12}{*}{ KEL. KOPO } & 8 & 1 & 2.806 & 1028 \\
\hline 2 & & 5 & 2 & 1.582 & 352 \\
\hline 3 & & 6 & 3 & 2.406 & 197 \\
\hline 4 & & 10 & 4 & 3.210 & 985 \\
\hline 5 & & 7 & 5 & 2.066 & 119 \\
\hline 6 & & 5 & 6 & 3.633 & 311 \\
\hline 7 & & 12 & 7 & 2.219 & 1105 \\
\hline 8 & & 8 & 8 & 2.075 & 351 \\
\hline 9 & & 7 & 9 & 2.299 & 243 \\
\hline 10 & & 5 & 10 & 2.379 & 540 \\
\hline 11 & & 5 & 11 & 1.796 & 851 \\
\hline 12 & & 8 & 12 & 2.575 & 725 \\
\hline & Jumlah & 86 & 12 & 29046 & 6807 \\
\hline
\end{tabular}

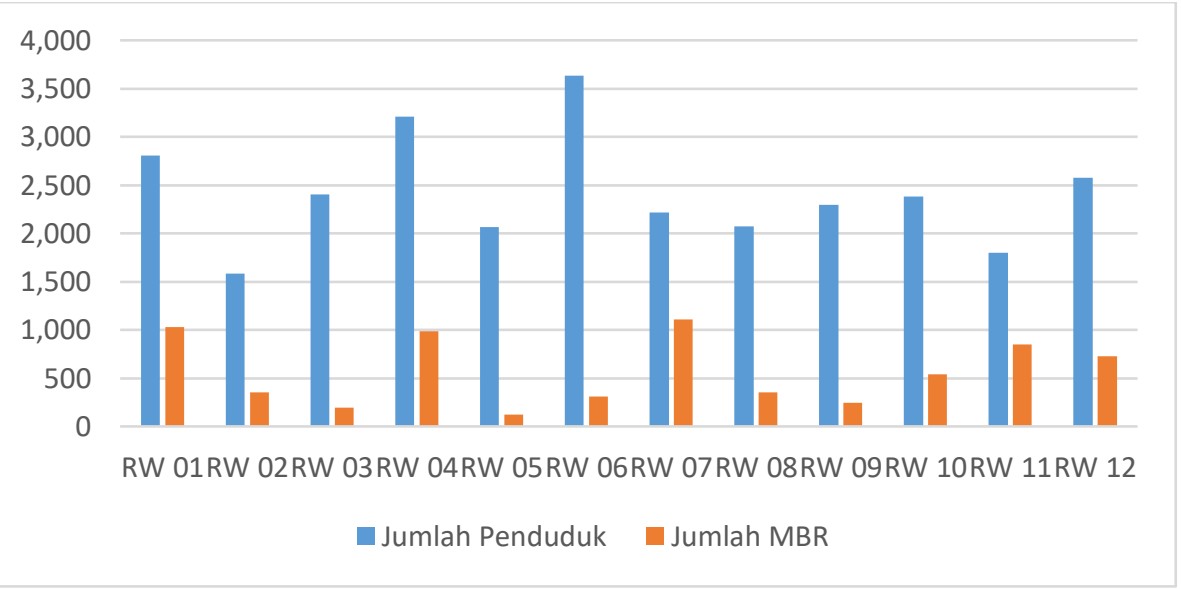

Gambar 12 Grafik Jumlah penduduk berdasarkan MBR

c. Potensi Sosial, Ekonomi dan Sumber Daya Alam Kelurahan Kopo

- Banyak terdapat UKM yang bergerak dalam usaha makanan dan konveksi

- Banyak terdapat perkantoran, bank dan ruko

- Masyarakat memiliki jiwa wirausaha

- Masyarakat yang agamis

- Masyarakat memiliki rasa ingin membangun daerahnya

- Masyarakat memilki rasa seni dan budaya

- Termasuk dalam kawasan ekonomi perdagangan dan jasa

- Banyaknya masyarakat pengrajin (Home Industry)

- Adanya lembaga kemasyarakatan

\subsubsection{Analisisi Tapak}

a. Strenghts

- Berada di tengah masyarakat yang memiliki nilai budaya dan agamis.

- Berpotensi menjadi citra kampung kota.

- Dekat dengan terminal Leuwi panjang dan Jalan Nasional. 
b. Opportunities

- Terletak di SWK Tegallega sehingga dekat dengan Pusat Kota.

- Fasilitas Umum disekitar site cukup lengkap bisa dicapai dengan waktu lebih-kurang dari 10 menit.

- Terletak di sekitar potensi home industry.

c. Weaknesses

- Landasan peraturan pembangunan pada tapak sudah terancang dengan baik.

- Fasilitas sarana pengelolaan Limbah sekitar area tapak yang kurang baik.

d. Threats

- Fasilitas hydrant pada area sekitar tapak belum terdeteksi.

- Area sekitar tapak banyak permukiman kumuh dan padat.

- Tapak berada di area beresiko banjir.

4.2 Gubahan Massa

a. Gubahan Massa 1

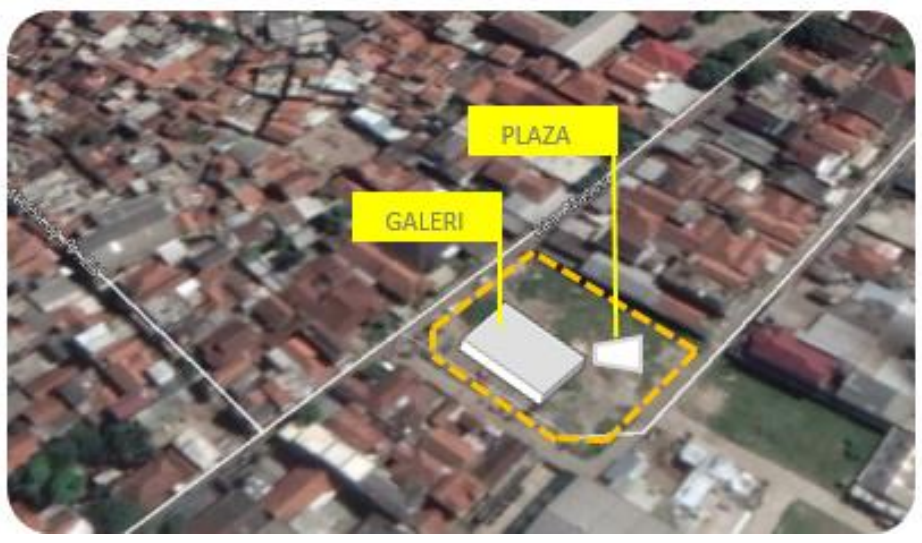

Gambar 6 Gubahan Massa 1

Merespon adanya bangunan komersial serta hunian yang berada di Jl. Madesa. Sepanjang sisi tapak yang bersebelahan dengan jalan tersebut digunakan untuk sirkulasi pejalan kaki, sirkulasi kendaraan mobil, motor, sepeda dan servis. Galeri, Plaza, Area Komersial di letakan sesuai dengan prioritas publik-privatnya pada tapak.

b. Gubahan Massa 2

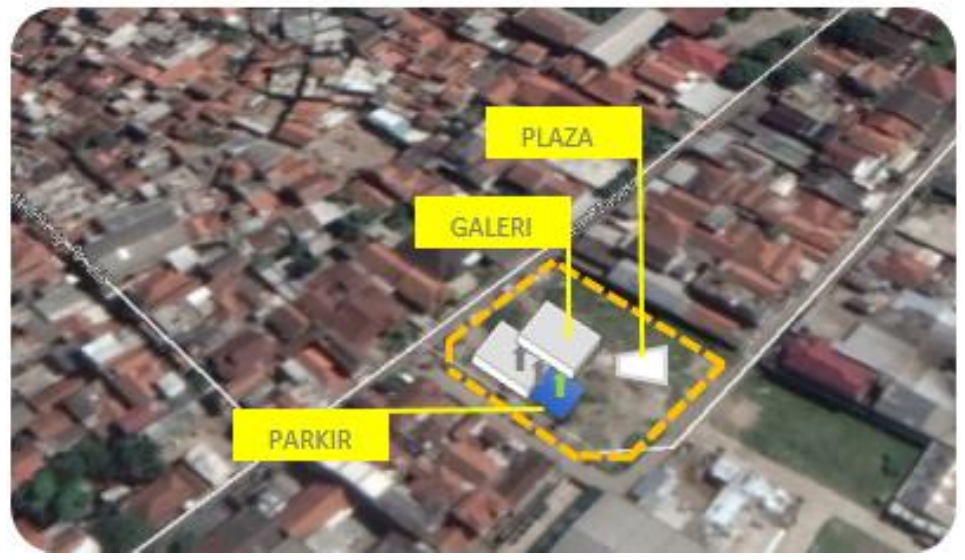

Gambar 7 Gubahan Massa 2

Massa bangunan dinaikan diatas tanah dengan gaya pilotis agar bangunan terhindar dari banjir yang sering melanda kelurahan Kopo. Hal ini juga dilakukan agar lebih banyak porsi pencahayaan alami dan di bagian bawah bangunan mendapatkan ruang untuk tempat parkir kendaraan.

c. Gubahan Massa 3 


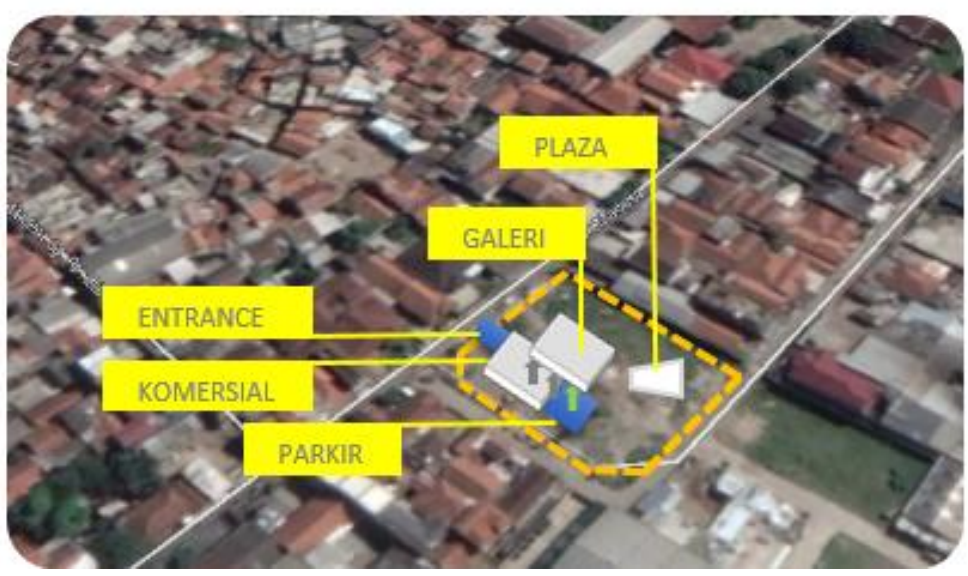

Gambar 8 Gubahan Massa 3

Massa komersial diletakkan di depan dengan diorama pada art corridor sebagai point of interest area komersial sehingga pengunjung memiliki pengalaman yang mengesankan. Selain itu merespon hunian lain yang berada di sepanjang Jl. Madesa. Sepanjang sisi tapak yang bersebelahan dengan jalan lingkungan digunakan untuk sirkulasi penjalan kaki, sirkulasi kendaraan mobil, motor, sepeda dan servis.

d. Gubahan Massa Final

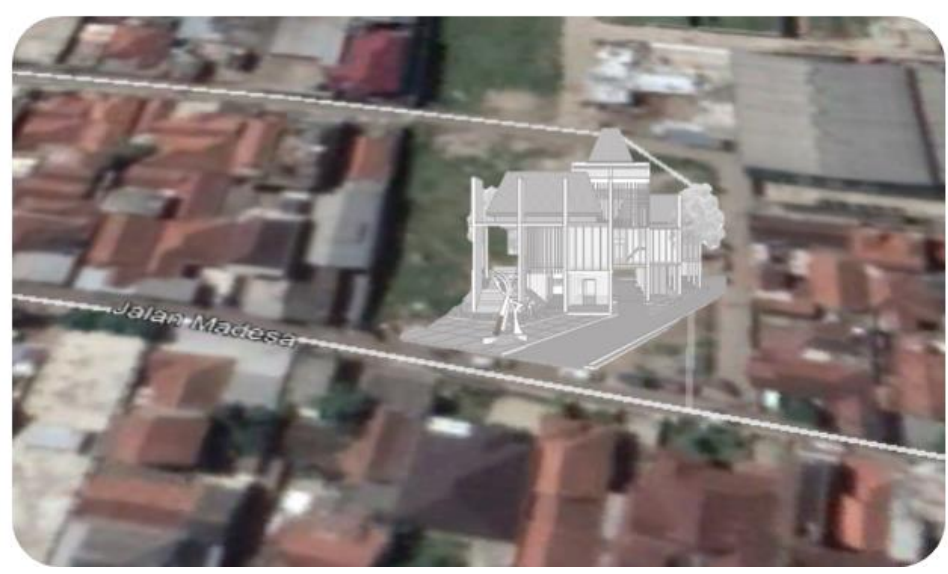

Gambar 9 Gubahan Massa Final

Gubahan Massa Final memperhatikan ruang terbuka publik dan efesiensi sirkulasi udara. Terletak di tengah pemukiman padat penduduk yang tinggi, lokasi tapak berpotensi menjadi bangunan sebuah ruang terbuka publik di kawasan Kelurahan Kopo. Ketinggian massa bangunan turut merespon terhadap skyline kawasan sehingga mudah di temukan dari area luar ke dalam kawasan kelurahan Kopo.

Bentuk tapak cenderung luas namun dibutuhkan ruang terbuka hijau kawasan. Oleh karena itu konsep open space harus dilakukan se-efesien mungkin agar tidak banyak menghabiskan lahan tapak. Pada desain bangunan ini, setiap ruang pada bangunan memiliki sirkulasi udara alami namun tetap memperhatikan fungsi utama sebagai Galeri wadah potensi home industry.

\subsection{Pengguna Bangunan Galeri}


Dalam perencanaan dan perancangan Galeri kopo ini memperhatikan pengguna sebagai pengelola, penyewa dan pasar galeri, diantaranya sebagai berikut.

\begin{tabular}{|c|}
\hline $\begin{array}{ll}\text { KEY } & \text { PATNERS } \\
\text { - } & \text { Pemerintah } \\
& \text { Setempat } \\
\text { - } & \text { Investor } \\
\text { - } & \text { Marketing } \\
\text { - } & \text { Penggiat Usaha } \\
& \text { Home Industry } \\
\text { - } & \text { Akademisi } \\
\text { - } & \text { Dll }\end{array}$ \\
\hline $\begin{array}{ll}\text { KEY } & \text { ACTIVITIES } \\
\text { - } & \text { Marketing } \\
\text { - } & \text { Workshop } \\
\text { - } & \text { Galeri } \\
\text { - } & \text { Ruang Komunal }\end{array}$ \\
\hline $\begin{array}{ll}\text { KEY } & \text { RESOURCES } \\
\cdot \quad & \text { Branding \& } \\
& \text { Design } \\
\cdot \quad & \text { Bussiness Center }\end{array}$ \\
\hline
\end{tabular}
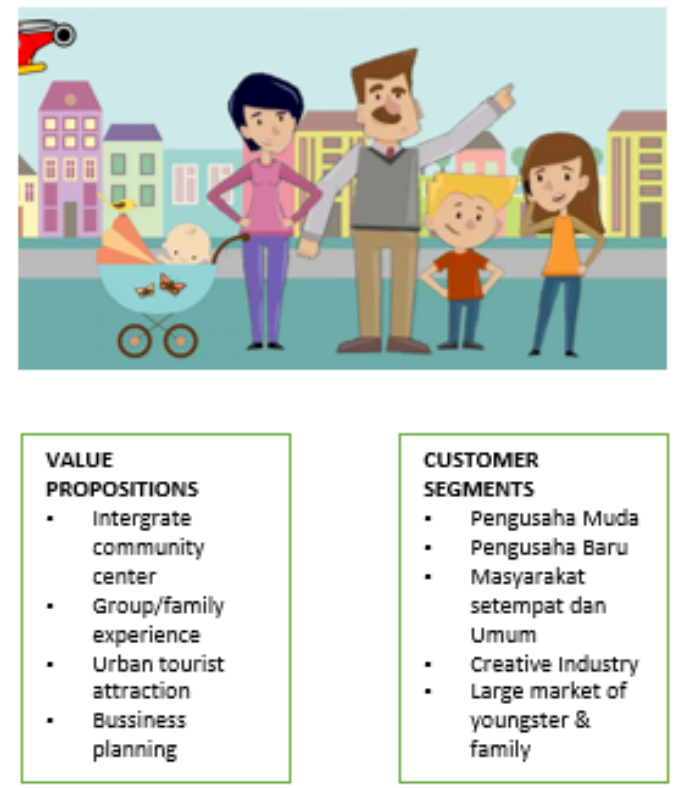

Gambar 10 Klasifikasi Pengguna Bangunan

\begin{tabular}{|c|}
\hline $\begin{array}{l}\text { CUSTOMER } \\
\text { RELATIONSHIPS } \\
\text {. CSR } \\
\cdot \text { Community } \\
\text { Event } \\
\text {. Pengusaha }\end{array}$ \\
\hline $\begin{array}{ll}\text { REVENUE STREAMS } \\
\text { - } & \text { Parking } \\
\text { - } & \text { Space Rent } \\
\text { - } & \text { Tenant } \\
\text { - } & \text { Membership } \\
\text { - } & \text { Event } \\
\text { - } & \text { Service fee }\end{array}$ \\
\hline $\begin{array}{ll}\text { COST STRUCTURE } \\
\text { - } & \text { Maintenance fee } \\
\text { - } & \text { Salary } \\
\text { - } & \text { Operation cost } \\
\text { - } & \text { Marketing cost } \\
\text { - } & \text { Technology cost } \\
\text { - } & \text { Legal cost }\end{array}$ \\
\hline
\end{tabular}

\subsection{Makna Bangunan}

Ditengah kesibukan kehidupan lingkungan urban di Bandung, seringkali pengusaha mikro mencari keseimbangan antara work life, personal life serta brand usaha. Adanya pandemic COVID-19 ini juga banyak membuat masyarakat dan pengusaha mikro maupun makro tidak bisa pergi jauh ke luar tempat tinggal mereka. Menyikapi hal ini, bangunan dengan fungsi wadah potensi home industry menjadi salah satu solusi bagi pengusaha mikro dan masyarakat yang akan memulai usaha. Di bangun dengan pendekatan perancangan partisipatif akan menambah sense of belonging masyarakat sekitar serta pentagonal stake holder didalamnya(Pigawati, 2015).

Keberadaan fungsi galeri, workshop, komersial pada rancangan ini memungkinkan penggiat home industry berkembang dan inovatif, serta dapat menguatkan bisnisnya pada area komersial dan business sharing yang dilakukan di business center. Fasilitas ini diharapkan mampu membangun komunitas setempat dengan kehidupan yang sehat dan seimbang bagi pengguna dan masyarakat kelurahan Kopo.

\section{Kesimpulan}

Berdiri dilahan 0.18 Ha di Kelurahan Kopo. Galeri Kopo adalah wadah potensi home industry dengan pendekatan partisipatif yang memiliki fungsi Galeri, Workshop, Diorama, Bussiness Center serta retail. Terletak di tengah pemukiman kelurahan Kopo Galeri Kopo menjadi tempat strategis akses terhadap jalan Soekarno-Hatta yang dapat dicapai dengan waktu yang relative singkat, serta integrasi dan konektivitas jalur pedestrian dan angkutan umum yang mudah dan nyaman bagi pengguna bangunan. Fasilitas berupa art corridor experience, Plaza untuk kegiatan bersama, serta area hijau yang terintegrasi dengan plaza menghadirkan sebuah tempat berkumpul yang memungkinkan pembangunan komunitas yang sehat dan berarti bagi masyarakat sekitar bangunan dan pengunjung..

\section{Ucapan Terima Kasih}

Saya ucapkan terima kasih kepada bapak Dr. Asep Yudi Permana, M.Ds sebagai dosen pengampu mata kuliah Studio Pendalaman Konteks, masyarakat di permukiman Kopo Kota Bandung sebagai naras umber yang telah banyak memberikan informasi dalam penyelesaian proyek desain ini. 


\section{Referensi}

Aset, J., Riset, A., \& Tahun, I. P. (2017). Analisa Pengaruh Intellectual Capital Terhadap Kinerja Pasar Dan Kinerja Keuangan Pada Perusahaan LQ45 Yang Terdaftar Di Bursa Efek Siti Nurhayati. 9(1), 133-172.

Christiyani, A. (2019). Pembangunan Sosial oleh Paguyuban Jamu Gendong Lestari melalui Sektor Ekonomi Kreatif. 10(2), 155-170.

E, N. G. T., Bhakti, T., Sumerta, D., Prevention, U., Taruna, K., \& Taruna, E. (2007). Efektivitas prog m penanggulangan penganggu n ng taruna "e taruna bhakti" desa sumerta kelod kecamatan denpasar timur kota denpasar. 49-57.

Ekosistem, M., Dan, E., Daya, S., \& Manoppo, P. G. (2014). (TRIANGEL PA’ DIOR) 1 Ekonomi dan Sumber Daya Manusia Komunitas Lokal." Riset menggunakan pendekatan kualitatif dengan metode Partisipatory Action Research. Pengumpulan data menggunakan ( kerjasama dan gotong royong : dimensi ekonomi ) dan Sitou Timou Tumou Tou ( hidup untuk Minahasa : berdayaguna dan berhasilguna dalam mengelola potensi ekologi-ekonomi-SDM. 41, 10-12.

Febrion, C., Wijaya, K., \& Sugandi, D. (2020). IDENTIFIKASI BANGUNAN KUMUH YANG MEMPENGARUHI KUALITAS LINGKUNGAN PERMUKIMAN TAMANSARI KOTA BANDUNG. Jurnal Arsitektur ARCADE, 4(3), 314-321.

Fitria, N., \& Setiawan, R. (2014). Identifikasi Karakteristik Lingkungan Permukiman Kumuh di Kelurahan Kapuk, Jakarta Barat. Jurnal Teknik ITS, 3(2), C240-C244.

Foran, M. (2009). Expansive Discourses: Urban Sprawl in Calgary 1945 - 1978

Health, T., \& Quality, C. (2003). Priority Areas for National Action. In Priority Areas for National Action. https://doi.org/10.17226/10593

Hutomo, M. Y., Pemberdayaan, S., \& Pemberdayaan, K. (2000). Pemberdayaan Masyarakat dalam Bidang Ekonomi : Tinjauan Teoritik dan Implementasi. 20, 1-11.

Pemerintah Republik Indonesia. (2011). Undang-Undang No 1 Tahun 2011 tentang PERUMAHAN DAN KAWASAN PERMUKIMAN.

Karir, M. P. (2013). Program Studi Akuntansi, Fakultas Ekonomi Universitas Semarang, Indonesia Jl. Soekarno Hatta Semarang. 5(2), 86-98.

Menteri Pekerjaan Umum dan Perumahan Rakyat Republik Indonesia. (2016). Peraturan Menteri Pekerjaan Umum dan Perumahan Rakyat Republik Indonesia Nomor 02/PRT/M/2016 Tentang Peningkatan Kualitas Terhadap Perumahan Kumuh dan Permukiman Kumuh (Issue June, p. 50061).

Niken Fitria, \& Setiawan, R. P. (2014). Identifikasi karakteristik lingkungan permukiman kumuh di Kelurahan Kapuk, Jakarta Barat. Jurnal Teknik Pomits, 3(2), 240-244.

Permana, A. Y., Susanti, I., \& Wijaya, K. (2019). Kerentanan Bahaya Kebakaran di Kawasan Kampung Kota. Kasus: Kawasan Balubur Tamansari Kota Bandung. Jurnal Arsitektur ZONASI, 2(1), 32-45. https://doi.org/10.17509/jaz.v2i1.15208

Permana, A. Y., Sumarna, N., \& Wijaya, K. (2017). Membangun Kampung Kreatif melalui Kolaborasi Mahasiswa dengan Masyarakat. Kasus: Kawasan Balubur-Tamansari Kota Bandung. Prosiding Seminar Nasional "Perencanaan Pembangunan Inklusif Desa-Kota," 51-58.

Permana, A. Y. (2012a). Eco-architecture Sebagai Konsep Urban Development di Kawasan Slums dan Squatters Kota Bandung. September, 1-11.

Permana, A. Y. (2012b). Peran Ruang Terbuka Publik Di Kawasan Slums dan Squatters Sebagai “ Ruang Ketiga ” (Kasus : Kawasan Bantaran Sungai Cikapundung di Kota Bandung ). 84-98.

Pigawati, R. N. B. (2015). Kajian Karakteristik Kawasan Pemukiman Kumuh Di Kampung Kota (Studi Kasus: Kampung Gandekan Semarang). Teknik Perencanaan Wilayah Kota, 4(2), 267-281.

Purnomo, R. A., Si, M., \& Indonesia, P. P. (n.d.). Ekonomi Kreatif.

Purwanto, E. (Universitas D., \& Sukawi (Universitas Diponegoro). (2009). Urgensi Kajian Jentrifikasi Ruang Kota: Belajar dari Model Kasus Negara Lain. In Proseding Diskusi Nasional Arsitek Sastra-Matra (pp. 155-162). Badan Penerbit Universitas Diponegoro.

Rofiana, V. (2015). Dampak Pemukiman Kumuh terhadap Kelestarian Lingkungan Kota Malang (Studi Penelitian di Jalan Muharto Kel Jodipan Kec Blimbing, Kota Malang. The Indonesian Journal of Public Administration (IJPA), 1(1), 40-57.

Surtiani, E. E. D. (2006). Faktor-Faktor yang Mempengaruhi Terciptanya Kawasan Permukiman Kumuh di Kawasan Pusat Kota. Universitas Diponegoro.

UN-Habitat. (2003). The Challenge of Slums: Global Report on Human Settlements. London: Earthscan Publications Ltd. 
Usaha, P., Kecil, M., Kandri, K., Gunungpati, K., \& Semarang, K. (2019). Pengembangan Ekonomi Masyarakat Melalui Pemberdayaan Usaha Mikro Kecil dan Menengah (Studi di Kelurahan Kandri Kecamatan Gunungpati Kota Semarang). 23(2), 152-157

Wijaya, K., \& Permana, A. Y. (2018). Textile Tourism Image as an Identity of Cigondewah in Bandung City. IOP Conference Series: Earth and Environmental Science. https://doi.org/10.1088/1755$1315 / 213 / 1 / 012012$

Wijaya, K., Permana, A. Y., \& Swanto, N. (2017). Kawasan Bantaran Sungai Cikapundung Sebagai Pemukiman Masyarakat Berpenghasilan Rendah (MBR) Di Kota Bandung. ARCADE, 1(2), 57-68. 